\title{
Type III glycogenosis presenting as liver disease in adults with atypical histological features
}

\author{
IW FELLOWS, JS LOWE, AL OGILVIE, A STEVENS, PJ TOGHILL, M ATKINSON \\ From the University Hospital, Queen's Medical Centre, Nottingham
}

SUMMARY Two cases of type III glycogen storage disease are reported in adults; the occurrence of cirrhosis in one case illustrates the potential development of chronic liver disease in this condition. The other was the oldest patient with this condition found in a review of published reports.

Electron microscopy of peripheral blood leucocytes to demonstrate excess glycogen was found to be a quick and useful aid to diagnosis. Histology of these adult cases showed a distribution of hepatocyte vacuolation which has not been previously recorded.

Type III glycogenosis is due to a deficiency of the debranching enzyme amylo 1-6 glucosidase which catalyses transfer of maltotriosyl residue from a side chain of glycogen to a main chain, leaving limit dextrin: the same enzyme then cleaves the solitary alpha $1-6$ linked residue from the limit dextrin. The disease was first described by van Creveld, and is protean in its manifestations. ${ }^{1-3}$ Typically it presents in childhood with growth retardation, hypoglycaemia and massive hepatomegaly. Symptoms of the disease tend to regress at puberty with a reduction in liver size and patients often survive into adulthood. Glycogen is found in excess in liver, skeletal muscle, cardiac muscle and leucocytes.

Diagnosis of the disease in life depends on showing abnormal carbohydrate metabolism with a normal increase in blood glucose following glucagon after a meal but not in the fasting state. Muscle and liver biopsy show characteristic changes. ${ }^{+}$Precise diagnosis depends on showing absence of the enzyme activity in blood leucocytes with increased red blood glycogen, a test which is not routinely available in most centres.

We report two cases of type III glycogenosis presenting in adults with diagnosis initially suggested on liver biopsy, supported in one case by electron microscopy of blood leucocytes.

\section{Case reports}

CASE 1

A 42-year-old man presented with abdominal pain and distension. There were no symptoms of

Accepted for publication 30 September 1982 hypoglycaemia, no excess alcohol intake and no family history of liver disease. At the age of two yr, hepatomegaly had been noted and at the age of $19 \mathrm{yr}$ he had been discharged from the RAF with a "large liver" without a firm diagnosis being made.

Examination showed a man with a bronzed complexion, spider naevi, leuconychia and ascites. $\mathrm{He}$ was found to be diabetic with a random blood glucose of $22.8 \mathrm{mmol} / \mathrm{l}$. The patient was mildly jaundiced: serum bilirubin $41 \mu \mathrm{mol} / \mathrm{l}$ (normal 5-17 $\mu \mathrm{mol} / \mathrm{l}$ ), alkaline phosphatase $340 \mathrm{IU} / \mathrm{l}$ (normal 46$190 \mathrm{IU} / \mathrm{l}$ ), alanine aminotransferase $30 \mathrm{IU} / \mathrm{l}$ (normal 2-24 IU/l). Investigations of the cause of his chronic liver disease were all negative including $\mathrm{HBsAg}$, alpha-1-antitrypsin, autoantibody screening, and iron and copper metabolism.

Liver biopsy showed cirrhosis with regeneration nodules and fibrous septa (Fig. 1). There was some bile duct proliferation with a patchy infiltrate of lymphocytes and neutrophils in portal areas. Moderate centrilobular cholestasis was seen. Hepatocytes showed striking empty vacuolation which was only partly due to glycogen. This produced a mosaic pattern which was non-uniform, the larger most vacuolated cells being seen around portal areas and fibrous septa. There was striking massive nuclear vacuolation by glycogen as shown by diastase PAS.

A glucagon stimulation test with $1 \mathrm{mg}$ intramuscular glucagon in the fasting state produced no rise in blood glucose but a $50 \mathrm{~g}$ galactose tolerance test showed a rise in blood glucose from $3 \cdot 1$ to $4 \cdot 3 \mathrm{mmol} / \mathrm{l}$.

The patient died four months after presentation with haematemesis from oesophageal varices. At necropsy his liver weighed $1450 \mathrm{~g}$ and showed an established cirrhosis. Liver glycogen content was 1.9 $\mathrm{g} \%$ (normal $1-5 \mathrm{~g} \%$ ) and skeletal muscle glycogen 


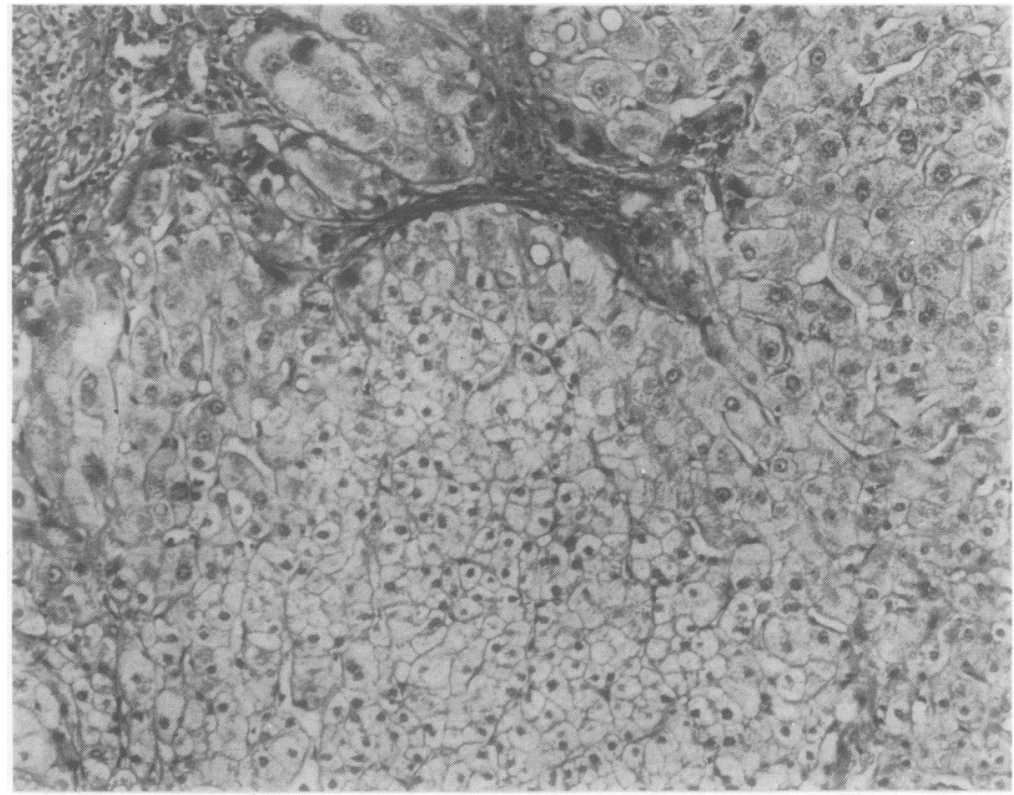

Fig. 1 Liver biopsy (patient 1) showing a non-universal pattern of hepatocyte vacuolation with fibrosis and nodule formation $\times 135$.

was $3.8 \mathrm{~g} \%$ (normal less than $1 \mathrm{~g} \%$ ). ${ }^{5}$ The apparently normal liver glycogen was felt to be due to fibrous tissue "diluting" increased glycogen in remaining hepatocytes.

\section{CASE 2}

A 65-year-old man presented following a faint. His general practitioner had recorded a blood glucose of $1.1 \mathrm{mmol} / \mathrm{l}$ by Dextrostix in the preceding month during a similar fainting episode. He had been noted to have an enlarged liver between the ages of four and $19 \mathrm{yr}$ but had passed an RAF medical examination Al at the age of $25 \mathrm{yr}$. At the age of $44 \mathrm{yr}$ he had undergone a Polya gastrectomy for duodenal ulceration. He had been well since that time apart from muscular weakness at the age of $61 \mathrm{yr}$ for which no cause had apparently been found. There was no family history of liver disease or evidence of excessive alcohol intake.

On examination the liver was enlarged $2 \mathrm{~cm}$ below the costal margin but there were no stigmata of chronic liver disease. Alkaline phosphatase was 301 IU/l, alanine aminotransferase $30 \mathrm{IU} / \mathrm{l}$, bilirubin 8 $\mu \mathrm{mol} / \mathrm{l}$. Further investigation of his liver enlargement including autoantibody screening, $\mathrm{HBsAg}$, alpha-1antitrypsin, iron and copper metabolism were normal. He was found to be mildly diabetic with an abnormal glucose tolerance test. A $50 \mathrm{~g}$ galactose tolerance test showed a normal rise in blood glucose. A 48 -h fast did not lower blood glucose below 3.7 $\mathrm{mmol} / \mathrm{l}$.
Liver biopsy showed normal architecture with prominent empty vacuolation of the cytoplasm of hepatocytes. This was non-uniform across the $\frac{\circ}{\varnothing}$ lobules, being most striking in periportal areas, and $\cong$ virtually absent in centrilobular areas (Fig. 2). This produced the "mosaic-like" pattern of cells described in type III glycogenosis. ${ }^{+}$There was also marked glycogen vacuolation of nuclei. No significant inflammatory component or fibrosis were seen in the biopsy.

A diagnosis of glycogen storage disease was supported by electron microscopy of leucocytes from $ᄋ$ a buffy layer preparation of blood. These observations support those of previous studies. ${ }^{6}$ 응 Glycogen appeared normal in lymphocytes and $>$ monocytes. There was excess of glycogen seen in neutrophil polymorphs. The excess of glycogen tended to be in coarser aggregates than in normal ${ }^{\circ}$ polymorphs and aggregated in the region of the $\tilde{N}$ smooth endoplasmic reticulum (Fig. 3). Neutrophils $\underset{\omega}{N}$ with a poorly segmented nucleus (younger cells) tended not to show this accumulation and differedo little from cells taken from normal individuals. Most $\underset{\mathbb{D}}{\overparen{D}}$ marked accumulations were seen in older cells with $\stackrel{\mathcal{\infty}}{+}$ segmented nuclei and also in effete polymorphs. 0 These findings were not present in cells from normal individuals.

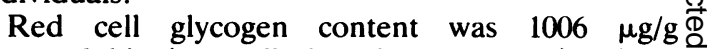
haemoglobin (normally less than $100 \mu \mathrm{g} / \mathrm{g}$ ). Direct amylo $1-6$ glucosidase assay on blood showed zero activity but phosphorylase was normal. In view of the응 


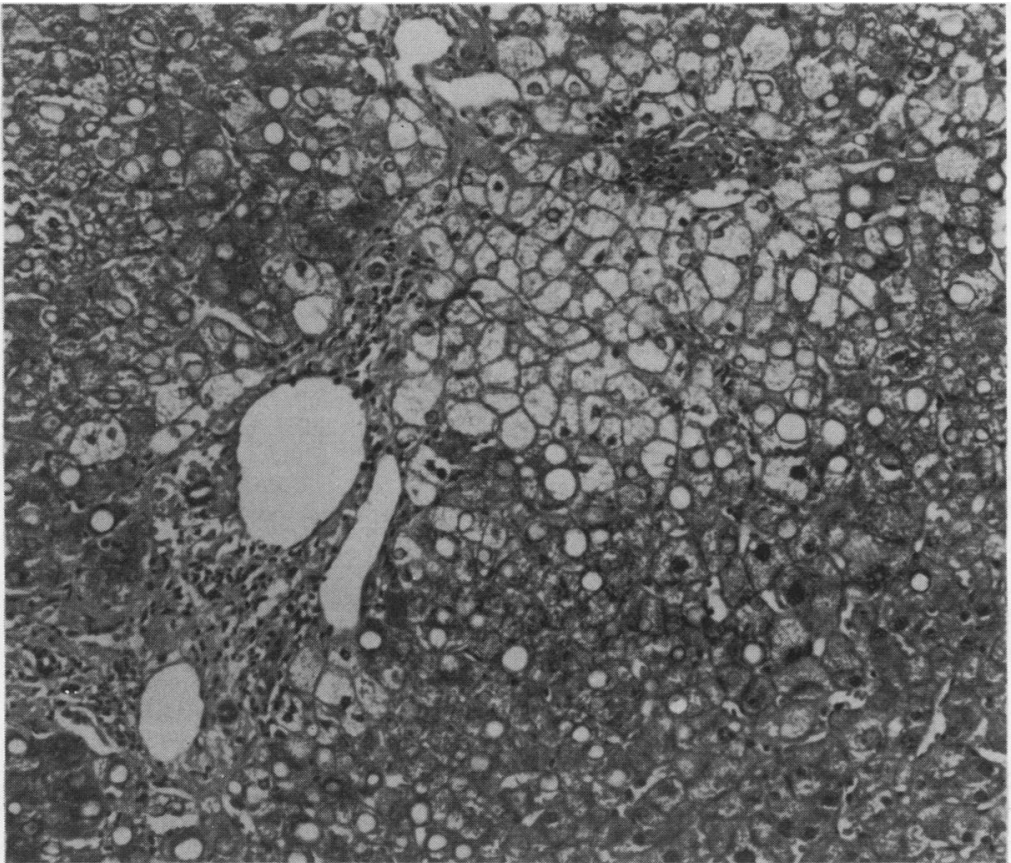

Fig. 2 Liver biopsy (patient 2) showing non-universal mosaic pattern of hepatocyte vacuolation with striking nuclear vacuolation $\times 135$.

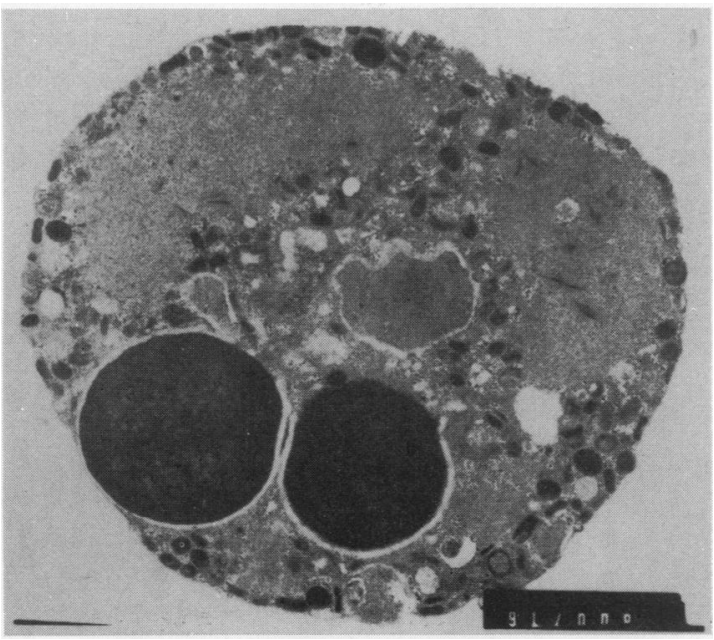

Fig. 3 Electron micrograph of effete polymorph neutrophil showing excess glycogen accumulation from patient 2 $\times 12500$.

failure to induce fasting hypoglycaemia it was felt that the patient's fainting attacks were due to dumping secondary to his Polya gastrectomy.

\section{Discussion}

Although debranching enzyme was not assayed in the first case the patient clearly had type III glycogenosis because of history, biochemical, and histological findings. Glucagon failed to cause a rise in blood glucose in the fasting state because glycogen molecules cannot be degraded further than limit dextrin without the action of debranching enzyme. ${ }^{7}$ The normal blood glucose response to a galactose load excluded galactosaemia. Excess glycogen in skeletal muscle excluded type VI glycogenosis where hepatic phosphorylase is deficient.

In the second case the finding of striking empty vacuolation in hepatocytes prompted a search for excess leucocyte glycogen. Old or effete normal leucocytes show a loss of glycogen from the cytoplasm whereas in the patient's old leucocytes excess glycogen was seen. The determination of glycogen was of most diagnostic value when looking at older or effete cells and we confirmed this to be good supporting evidence of a glycogenosis, the diagnosis being confirmed by direct assay of the enzyme in blood leucocytes at a specialist centre. Electron microscopy of buffy coat leucocytes is a quick and easy procedure which is readily available in most laboratories. It can be used as a screening test to support a diagnosis of glycogenosis before sending blood for an enzyme assay.

The classical description of liver histology in type III glycogenosis is universal vacuolation of hepatocytes forming a uniform mosaic pattern with peri- 
portal nuclear hyperglycogenation. ${ }^{4}$ In our two cases the hepatocyte vacuolation was not universal and tended to be related to portal areas and fibrous septa. Nuclear glycogen vacuolation was most marked in periportal areas. It may be that there is a universal uniform mosaic vacuolation in childhood which regresses in adult life as clinical manifestations of the disease regress. It is notable that the second patient described here is the oldest to have this type of disease in a review of published reports. ${ }^{2358}$

The two cases illustrate that type III glycogenosis can result in hepatomegaly with no overt alteration in liver function or may progress to cirrhosis. The potential to develop cirrhosis has been described, ${ }^{9}$ although this has been denied elsewhere. ${ }^{4}$

Striking vacuolation of hepatocytes on liver biopsy is a pointer to diagnosis of a glycogen storage disease and we feel that electron microscopy of leucocytes can provide important supporting evidence on which to base further investigation.

Professor AD Patrick kindly performed the analysis of red cell glycogen and leucocyte debranching enzyme and phosphorylase activity at the Institute of Child Health, Guilford Street, London WC1.

$\mathrm{Mr} \mathrm{W}$ Brackenbury took photographs of Figs. 1 and 2. Mr S Terras prepared ultrathin sections of buffy coat for EM and provided Fig. 3.

References

' Van Creveld S. Overeen bijondere stoornis in de koolhydratenstofiiseling in de kinderleeftijd. Mandschr Neder Geneeskunds 1928;15:349.

2 Hug G. Glycogen storage diseases. Birth Defects 1976;12:145-75.

${ }^{3}$ Senior B, Sedeghi-Nejad A. The glycogenoses and other inherited disorders of carbohydrate metabolism. Clin Perinatol 1976;3:79-98.

+ McAdams AJ, Hug G, Bove KE. Glycogen storage diseases types I to X: criteria for morphological diagnosis. Hum Pathol 1974;5:463-87.

s Levin S, Moses SW, Chayoth R, Jogoda N, Steinitz K. Glycogen storage disease in Israel. A clinical, biochemical and genetic study. Isr J Med Sci 1967;3:397-410.

- Garancis J, Panares B, Good TA, Kuzma JF. Type III glycogenoisis. A biochemical and electron microscopic study. Lab Invest 1970;22:268-477.

' Fernandes J, Koster JF, Grose WFA, Sorgedrager N. Hepatic phosphorylase deficiency. Its differentiation from other hepatic glycogenoses. Arch Dis Child 1974;49:186-91.

${ }^{*}$ Howell RR. The glycogen storage diseases. In: Stanbury JB, Wyngaarden JB, Fredrickson DS, eds. The metabolic basis of inherited disease 4th ed. New York: McGraw-Hill, 1978:137-59.

- Starzl TE, Putnam CW, Proter KA, et al. Portal diversion for the treatment of glycogen storage disease in humans. Ann Surg 1973;178:525-39.

Requests for reprints to: Dr IW Fellows, Department of Medicine, University Hospital, Queen`s Medical Centre, Nottingham N67 2UH, England. 